\title{
RESPIRATION IN THE HIGHER PLANT
}

AEROBIC breakdown of sugars can conveniently be studied in two stages--glycolysis followed by oxidative processes. Both phases have been discussed recently (New Phyt., $39 ; 1940$ ). James and James (loc. cit., p. 266), continuing the work on pyruvic acid metabolism, have shown that inactivation of carboxylases in barley, either by acetaldehyde or by one of a number of aromatic sulphonic acids, leads to accumulation of pyruvic acid in amounts which enable the isolation of identifiable hydrazones. The position of pyruvic acid in the aerobic respiration of barley is now considered sufficiently clear by James and his collaborators to allow the statement of a chain of reactions involving ascorbic acid oxidase :

hexose $\overrightarrow{1}$ hexosediphosphate $\overrightarrow{2}$ triosephosphate $\overrightarrow{3}$ phosphoglycerate

$\downarrow$

pyruvic acid.

Reaction 3 involves the oxidase. Pyruvic acid is metabolized to acetaldehyde and carbon dioxide in the usual way, though it is considered that the former may not be respired directly in young tissues, but may rather be concerned with synthesis (Report of Soc. for Exp. Biol., loc. cit., p. 335). The oxidative stage in plant respiration involves one or more of a series of enzymes.

In a review of the various possibilities Boswell and Whiting (New Phyt., 39, 241; 1940) discuss the three principal oxidase systems and also other systems of less importance. They base their study on the observation of Szent Györgyi that only catechol compounds, ascorbic acid, and dihydroxymaleic acid give a pronounced violet coloration with ferrous salts in neutral solution. For example, in catechol, an iron-catechol complex is formed, and this, by electronic interchange between $\mathrm{Fe}^{++}$, $\mathrm{C}_{6} \mathrm{H}_{4} \mathrm{O}_{2}-$ and $\mathrm{Fe}+++$, eventually releases free orthoquinone. Catechol oxidase is considered to act simply as a copper compound effecting oxidation by such complex formation, oxygen addition, and electron transfer. The importance of the three compounds listed above seems to lie in the fact that each carries a dihydroxy grouping. Oxidases may thus be regarded as protein plus firmly attached metal plus loosely attached prosthetic group or coenzyme containing a dihydroxy group. The chemical possibilities underlying oxidation by catechol oxidase, dihydroxymaleic oxidase, and ascorbic oxidase are discussed in some detail.

There is, however, no clear evidence that these last two are widely operative in plants. The more important catechol oxidase contains no peroxidase ; it produces quinones, which act as hydrogen aceeptors, and perhaps also hydrogen peroxide which is removed either by catalase or peroxidase. Among other iron complexes, the iron-porphyrins cytochrome and peroxidase receive most attention. The latter is státed to catalyse oxidations in the presence of hydrogen peroxide only. It may thus play a part in the catechol oxidase system by increasing the production of quinones. It is suggested that the respiratory chromogens of Palladin may be prosthetic groups loosely attached to unknown proteins.

\section{NEW WORLD POPULATIONS}

$\mathrm{R}$ AYMOND PEARL has examined statistics of the populations of the western hemisphere, the New World, in relation to corresponding figures for the old World, so far as available, and taking certain bases of comparison as indexes of 'youthfulness' or the reverse in the populations compared (Human Biology, 12, 3; 1940). Five of six attributes of populations generally regarded as of primary importance have been taken, the sixth quality being omitted on account of the difficulty of scientific appraisement.

(1) Density of aggregation per unit of land area. Central America, 37 persons per sq. mile; North America, 17 per sq. mile; South America, $12 \cdot 8$ per sq. mile, as against Europe, 189.5 per sq. mile ; Asia, 108.6 per sq. mile (U.S.S.R. territory being omitted in both these). Broadly speaking, a relatively low density implies a comparatively youthful and vigorous stage of population.

(2) Net percentage rate of growth per unit of time. The comparative levels of population growth-rates may be taken as the clearest and least equivocal expressions of innate physical vigour, combining the forces of natality and mortality. The higher birth-rates are found among the biologically more vigorous, whereas in enfeebled populations the death-rates tend to be low. In such figures as are available from 1900 until 1935, the most impressive result is a well-nigh universal decline, but even so the population of the New World is growing at a.much faster rate than that of Europe. The figures available are: Europe,
1900-10, 0.95 per cent; 1910-20, 0.22 per cent; 1920-35, 0.81 per cent. Western hemisphere, 1900-10, 2.24 per cent; 1910-20, 1.72 per cent; 1920-35, 1.68 per cent.

(3) The natural rate of increase by excess of births over deaths. This gives insight into the capacity for growth and general biological healthiness of a population at a given time. Figures for 116 countries are considered and again confirm the general biological healthiness of New World populations. The average vital index for the western hemisphere is $175 \cdot 72$ as against Europe 151, Asia (sampled) 152, Africa (sampled) 162, or a grand average for the eastern hemisphere of $152 \cdot 38$.

(4). Age composition. This attribute is of vital importance as reflecting the mass outlook on life and the psychology generally, as populations containing a relatively high proportion of young people are apt to display progressive and hopeful attitudes and to be aggressive in social and economic pioneering. Taking the life-cycle as falling into three divisions, the figures for the western hemisphere are : pre-reproductive, $39 \cdot 0$ per cent ; reproductive, $50 \cdot 6$ per cent; post-reproductive, 10.4 per cent. For Europe, pre-reproductive, $27 \cdot 9$ per cent ; reproductive, 52 per cent; post-reproductive, $20 \cdot 1$ per cent.

(5) Racial composition. As applied to the western hemisphere, just under 65 per cent of the combined total population is classified or regarded as white without other racial admixture. 